\title{
Predicting the Tensile and Air Permeability Properties of Woven Fabrics Using Artificial Neural Network and Linear Regression Models
}

\section{Ghada Ali Abou-Nassif*}

Fashion Design Department, Design and Art Faculty, King Abdul Aziz University, Jeddah, Saudi Arabia

\begin{abstract}
The objective of this paper is to investigate the predictability of some of woven fabric properties using artificial neural network (ANN) and regression models. For achieving this purpose, a neural network with three layers was adopted. The regression model was of type a multiple - linear regression one. The independent variables were weft yarn count, twist multiplier and weft density; and the dependent ones were tensile strength, breaking extension and air permeability of the woven fabrics. The ANN and regression models were assessed using the Root means square error (RMSE) and the coefficient of determination (R2-value). The findings of this study revealed that ANN is superior to regression model in predicting the woven fabric properties.
\end{abstract}

Keywords: Neural networks; Back-propagation; Woven fabrics properties; Tensile strength; Air permeability

\section{Introduction}

\section{Artificial neural network}

Artificial Neural Networks (ANNs) are algorithmic structures derived from a simplified concept of the human brain structure. They belong to the Soft Computing family of methods, along with fuzzy logic/ fuzzy control algorithms and genetic algorithms [1]. They all share an iterative, non-linear search for optimal or suboptimal solutions to a given problem, without the presupposition of a model of any type for the underlying system or process [2]. Various different ANN types have already been successfully employed in a wide variety of application fields [3]. Major ANN functionalities are: function approximation which can be exploited in system input-output modeling and prediction, and pattern recognition and classification problems [4].

The structure or 'architecture' of an ANN contains a number of nodes, called neurons, organized in a number of layers and interconnected to form a network. Each neuron receives connections from other neurons and/or itself, each with an associated weight. The interconnectivity defines the topology of the ANN. The weights represent information being used by the neural network model to solve a problem. One of the central issues in neural network design is to utilize systematic procedures (a training algorithm) to modify the weights directly from the training data without any assumptions about the data's statistical distribution [5].

There are different kinds of topologies and training algorithms but the multi-layered feed-forward neural network with back-propagation learning algorithms is more popular and commonly used [6]. In this structure, the neurons are located in layers and from one layer to another one connected with each other with links to carry the signals between them. There is a weight for each connection link which acts as a multiplication factor to the transmitted signal. An activation function such as linear or sigmoid is applied to each neuron's input to determine the output signal. Usually a feed forward neural network consists of several layers of nodes, one input layer, one output layer and some hidden layers in between.

The training of a neural network by back-propagation involves three stages: The feed-forward of the input training pattern, the calculation and back-propagation of the associated error, and the adjustment of the weights. The calculation of error vector to adjust the weights is done according to the calculated mean square error (MSE) form the difference between actual and predicted outputs according to the following relationship.

$$
\mathrm{MSE}=\frac{1}{N} \sum_{i=1}^{N}\left(y_{i}-x_{i}\right)^{2}
$$

Where $\mathrm{N}=$ the number of observations, $\mathrm{y}_{\mathrm{i}}=$ the neural network predicted values, and $\mathrm{x}_{\mathrm{i}}=$ the actual target values.

In the backward pass, this error signal is propagated backwards to the neural network and the synaptic weights are adjusted in such a manner that the error signal decreases with each iteration process. Thus, the neural network model approaches closer and closer to producing the desired output. The corrections necessary in the synaptic weights are carried out by a delta rule, which is expressed by the following equation.

$$
\Delta \mathrm{W}_{\mathrm{ji}(\mathrm{n})}=-\eta\left[\frac{\partial(M S E)}{\partial \mathrm{W}_{\mathrm{ji}(\mathrm{n})}}\right]
$$

Where $\mathrm{W}_{\mathrm{ii}(\mathrm{n})}$ is the weight connecting the neurons $\mathrm{j}$ and $\mathrm{i}$ at the $n$th iteration; $\Delta \mathrm{W}_{\mathrm{ji}(\mathrm{n})}^{\mathrm{ji}(\mathrm{n})}$, the correction applied to $\mathrm{W}_{\mathrm{ji}(\mathrm{n})}$ at the nth iteration; and $\eta$, a constant known as learning rate $[7,8]$.

\section{Prediction of yarn and woven fabric properties}

Generally, modeling and prediction of yarn and fabric properties based on fiber properties, fabric characteristics and process parameters have been considered by many researchers. Over the years, one of the first approaches has been the use of mechanistic models. In this category, some studies such as the work of Alsaid A Almetwally [9] and Pinar [10] to predict cotton yarn strength and spinning quality, Hearle, El-Behery and Thakur [11] in relation to structural mechanics

*Corresponding author: Ghada Ali Abou-Nassif, Fashion Design Department Design and Art Faculty, King Abdul Aziz University, Jeddah, Saudi Arabia, Tel: 966-2-640-0000; E-mail: dr_ghada2013@yahoo.com

Received July 16, 2015; Accepted July 27, 2015; Published August 16, 2015

Citation: Abou-Nassif GA (2015) Predicting the Tensile and Air Permeability Properties of Woven Fabrics Using Artificial Neural Network and Linear Regression Models. J Textile Sci Eng 5: 209. doi:10.4172/2165-8064.1000209

Copyright: () 2015 Abou-Nassif GA. This is an open-access article distributed under the terms of the Creative Commons Attribution License, which permits unrestricted use, distribution, and reproduction in any medium, provided the original author and source are credited. 
of fibers, yarns, and fabrics, the prediction of yarn strength by Frydrych [12], and works performed by Vitro et al., [13] Kim and El-sheikh [14] and Yong Ku Kim [15] and El-sheikh [16] can be mentioned. However, statistical regression models for this purpose have been used by some researchers, namely El-Mogahzy [17], Hunter [18] and Alsaid Ahmed Almetwally [19,20] and M M Mourad [21].

The limitation of mechanistic and statistical regression models was described in previous works $[22,23]$. ANNs, genetic algorithm, and fuzzy set theory are presented as attractive alternatives for predictive modeling. ANN algorithms have been used by many researchers for modeling the different textile processes, especially for predicting different kinds of yarn and fabric properties. Alsaid Ahmed Almetwally [5] compared between artificial neural networks and regression models in relation to the tensile properties of cotton/spandex core spun yarns. The results of his study revealed that ANN has better performance in predicting comparing with multiple linear regressions. ANNs were also used to predict the stress strain curve of the woven fabrics [24].

Fabric hand is a property that combines the mechanical properties of a fabric with the sensory perception of the fabric by the humans when they touch it. Fabric hand was predicted by using artificial neural networks by Youssefi and Faez [25], Hui et al. [26], and Matsudaira [27]. Drapability is far the most complex mechanical property of the fabrics and it is essential for many applications of the textile fabrics. The prediction of the drape has been made using ANNs [28].

\section{Materials and Methods}

In this study eighteen fabric samples were woven. All fabric samples were produced from Egyptian cotton of type Giza 80. The properties of cotton used to spin the weft and warp yarns from which the fabric samples are woven, were listed in Table 1. All warp yarns were made with the same English count, but the weft yarns were spun from three different counts. Each weft yarn also has two twist multipliers. Each fabric sample was woven with three different densities for the weft yarns. Generally, fabric samples used in this study were woven on Rapier weaving machine of model Picanol Gamamax with the following particulars:

Warp yarn count: $30 / 1 \mathrm{Ne}$

Weft yarn counts: $24 / 1 \mathrm{Ne}, 30 / 1 \mathrm{Ne}$, and 36/1 Ne.

Warp yarn density: 108 ends/inch.

Weft yarn densities: 50, 60, and 70 ppi.

Twist multiplier of warp yarns: 4 .

Twist multipliers of weft yarns: 3.8 and 4.2.

Weave structure: plain $1 / 1$.

Warp width: $176.8 \mathrm{~cm}$.

Number of harness: 6

\begin{tabular}{|l|c|}
\hline Parameter & Value \\
\hline Micronaire value & 4.67 \\
\hline Mean length (mm) & 28.7 \\
\hline Uniformity Index (\%) & 82.4 \\
\hline Strength (g/tex) & 34.1 \\
\hline Elongation (\%) & 7.8 \\
\hline Maturity \% & 86 \\
\hline Fineness (mtex) & 185 \\
\hline
\end{tabular}

Table 1: Characteristics of cotton used to make the fabric samples.

\section{Reed count: 20.5 dent $/ \mathrm{cm}$}

Fabric width: $170 \mathrm{~cm}$ (Table 1).

Since the variation in the fabric samples were conducted in the weft direction, then testing the fabric properties were carried out in the same direction. Before testing, all fabric samples were conditioned and then tested under standard condition of $20 \pm 2^{\circ} \mathrm{C}$ and $65 \pm 5 \%$ relative humidity. Tensile strength and breaking extension measurements of the fabric samples were executed by standard strip method on an Instron 4411 Tester (Instro Inc., USA) in accordance with ASTM D1682; ten individual readings for each fabric sample were taken and averaged. The air permeability was measured by shierly Air permeability Tester according to ASTM D737-04; ten readings for each fabric sample were recorded and averaged.

\section{Neural network design}

Architecture: First, the size of the network must be determined by the number of hidden layers and the number of neurons in these layers. A network with three layers is sufficient for most practical applications. The number of input neurons normally corresponds to the number of input variables of the process to be modeled. In selecting the output neurons, note that it is generally inadvisable to train a network for several tasks simultaneously. In this study we have selected a network with three layers: an input layer with three neurons, hidden layer with 5 neurons, and an output layer with one neuron corresponding to one dependent variable subject to the analysis at a time.

Learning strategy and transfer functions: Before learning, the whole experimental data were segregated into training, validation, and testing patterns: $60 \%$ of the patterns were randomly selected for training, $20 \%$ were for testing the neural network, and the remaining $20 \%$ of patterns were for validating the model's performance [5]. Training is an important feature of neural networks. The objective of the training process is to minimize the squared error between the network output and the desired output. This is done by adjusting the connection weights across the network. The validation set is a part of the data used to tune network topology or network parameters other than weights. For example, it is used to define the number of units to detect the moment when the neural network performance started hidden to deteriorate. To choose the best network (i.e. by changing the number of units in the hidden layer), the validation set is used. Whereas, the test set is a part of the input data-set used to test how well the neural network will perform on new data. The test set is used after the network is ready (trained), to test what errors will occur during future network application. This set is not used during training and thus can be considered as consisting of new data entered by the user for the neural network application. The learning method is backpropagation with Levenberg-Marquardt algorithm. Three of the most commonly used transfer functions are linear, sigmoid, and tanh:

Linear: $f(x)=x$

Sigmoid: $\mathrm{f}(\mathrm{x})=\frac{1}{\left(1+e^{-x}\right)}$

Tanh: $\mathrm{f}(\mathrm{x})=\frac{\left(e^{x}-e^{-x}\right)}{\left(e^{x}+e^{-x}\right)}$

The topology architecture of feed-forward three-layered backpropagation neural network is illustrated in Figure 1.

\section{Performance of the neural network}

The performance of the ANN was assessed using the root mean 
square error (RMSE), and the coefficient of determination according the following formulas:

Root mean square error: $\mathrm{RMSE}=\sqrt{\frac{1}{N} \sum_{i=1}^{N}\left(y_{i}-x_{i}\right)^{2}}$

Coefficient of determination $=\frac{S S_{\text {reg }}}{S S_{\text {total }}}$

Where $\mathrm{N}=$ the number of observations, $\mathrm{y}_{\mathrm{i}}=$ the neural network predicted values of fabric properties, $\mathrm{x}_{\mathrm{i}}=$ the actual values of fabric properties

\section{Statistical regression}

In this study, multiple-linear regression was used for developing three predictive models of fabric tensile strength, fabric breaking extension, and fabric air permeability. In this concern, the same sets of data used for evaluating ANN model were used in a multiple linear regression algorithm. Independent variables were weft yarn count $(\mathrm{Ne})$, weft density (ppi) and the twist multiplier of weft yarns. The following linear regression models correlate the fabric properties of woven fabrics with the independent variables, i.e. weft yarn count, weft density, and twist multiplier.

Tensile strength, $\mathrm{kg}=97.3-2.3 \times$ weft yarn count $+5.3 \times$ twist multiplier $+0.6 \times$ weft density

Breaking extension, $\%=31.2-0.2 \times$ weft yarn count $+1.1 \times$ twist multiplier $-0.14 \times$ weft density

Air permeability, $\left(\mathrm{cm}^{3} / \mathrm{cm}^{2} . \mathrm{sec}\right)=45.4+0.4 \times$ weft yarn count +5.2 $\times$ twist multiplier $-0.96 \times$ weft density

As seen from the regression models above, twist multiplier of weft yarns affected all fabric properties positively. However, weft yarn density affected breaking extension and air permeability negatively and affected the fabric tensile strength positively. Whereas weft yarns count

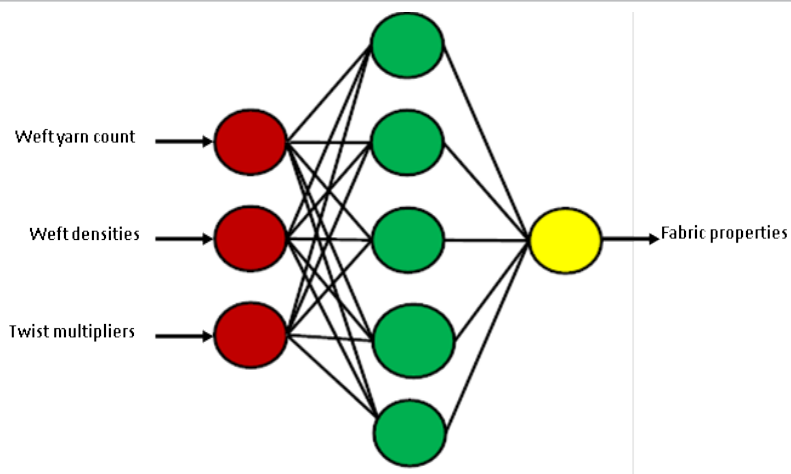

Figure 1: Artificial neural network architecture used influenced the tensile strength and breaking extension negatively; while air permeability is affected positively. The statistical analysis also revealed that yarn count accounts for $76 \%$ of the variability in fabric tensile strength and that twist multiplier accounted for 7\%, while weft density accounted for $52 \%$ of the variability in fabric tensile strength. With respect to breaking extension, it was determined that weft yarn count, twist multiplier and weft density accounted for $50 \%, 11 \%$ and $55 \%$ respectively of the variability in fabric breaking extension. Finally, it was found that weft yarn count, twist multiplier and weft density accounted for $23 \%, 12 \%$ and $92 \%$, respectively of the variability in fabric air permeability.

\section{Results and Discussion}

In this study, we have adopted a three-layer neural network consisting of a three-input layer, a 5-neuron hidden layer, and a oneneuron output layer at a time, focusing on fabric tensile strength $(\mathrm{kg})$, breaking extension (\%), and air permeability $\left(\mathrm{cm}^{3} / \mathrm{cm}^{2} . \mathrm{sec}\right)$. The neural network learning model is in accordance with the experiment data of three inputs and three targets, which are listed in Table 2 . The general view of the neural network used in this study is shown in Figure 1. The RMSE and coefficient of determination $\left(\mathrm{R}^{2}\right)$ were used to judge the performance of ANN and regression models (Table 2).

\section{Tensile strength}

Tensile strength has been accepted as one of the most important attributes of woven fabrics. It is the main characteristic that distinguishes it from non-woven and knitted fabric. The strength of a woven fabric depends not only on the strength of constituent yarns, but also on the yarn and fabric structure and many other factors [29].

The actual and predicted tensile strength values of woven fabric samples, according to the variation of the independent variables, using ANN and regression models and its performance are presented in Tables 3 and 4 and in Figure 2, respectively. The results revealed that ANN model gives the best performance with the least RMSE and highest $\mathrm{R}^{2}$ values. The values of the root mean square error were 3.1 and zero for regression and ANN models, respectively. The coefficient of determination values of regression and ANN models were found to equal 0.87 and 1 , respectively. This signifies that an artificial neural network model fits the data very well and it is better than the regression model in predicting the tensile strength of the woven fabrics.

From Table 3, it can be seen that the minimum and maximum absolute errors for regression model are 1.6 and $15.5 \%$, while the corresponding values for ANN model are zero and $6.1 \%$. This confirms that ANN model has a better predictive performance than regression analysis to predict the tensile strength of woven fabrics under study.

Figure 2 compares the predicted outputs of the ANN model and

\begin{tabular}{|c|c|c|c|c|c|c|}
\hline \multirow[t]{2}{*}{ Sample No. } & \multicolumn{3}{|c|}{ Inputs } & \multicolumn{3}{|c|}{ Targets } \\
\hline & Yarn count (Ne) & Twist multiplier & $\begin{array}{l}\text { Weft density } \\
\text { (ppi) }\end{array}$ & Tensile strength (kg) & $\begin{array}{l}\text { Breaking extension } \\
(\%)\end{array}$ & $\begin{array}{l}\text { Air permeability } \\
\left(\mathrm{cm}^{3} / \mathrm{cm}^{2} . \mathrm{sec}\right)\end{array}$ \\
\hline 1 & 24 & 4.2 & 50 & 39.33333 & 24.66667 & 30.33333 \\
\hline 2 & 30 & 3.8 & 50 & 33 & 22.00000 & 28.66667 \\
\hline 3 & 30 & 3.8 & 70 & 55.33333 & 19.33333 & 11.00000 \\
\hline 4 & 30 & 4.2 & 60 & 41.66667 & 21.66667 & 22.00000 \\
\hline 5 & 36 & 3.8 & 60 & 25 & 21.00000 & 19.66667 \\
\hline 6 & 36 & 3.8 & 70 & 31.66667 & 17.66667 & 13.33333 \\
\hline 7 & 36 & 4.2 & 70 & 36 & 18.33333 & 13.66667 \\
\hline
\end{tabular}

Table 2: Learning data of the back-propagation neural network for fabric tensile properties and air permeability. 


\begin{tabular}{|l|c|c|c|c|}
\hline \multirow{2}{*}{ Actual values } & \multicolumn{2}{|c|}{ Multi-linear regression } & \multicolumn{2}{|c|}{ Artificial neural network } \\
\cline { 2 - 5 } & $\begin{array}{c}\text { Predicted } \\
\text { value }\end{array}$ & $\begin{array}{c}\text { Absolute error } \\
\text { (\%) }\end{array}$ & $\begin{array}{c}\text { Predicted } \\
\text { value }\end{array}$ & $\begin{array}{c}\text { Absolute error } \\
\text { (\%) }\end{array}$ \\
\hline 54.66667 & 56.83333 & 3.963402 & 54.55063 & 0.212268 \\
\hline 39.33333 & 45.44444 & 15.53672 & 39.33333 & 0 \\
\hline 51.33333 & 54.72222 & 6.601734 & 48.21225 & 6.080026 \\
\hline 48.33333 & 47.55556 & 1.609179 & 48.33333 & 0 \\
\hline
\end{tabular}

Table 3: Tensile strength predicted by multi-linear regression and neural network.

\begin{tabular}{|l|c|c|}
\hline Statistical parameters & Regression & ANN \\
\hline Coefficient of determination, $\mathrm{R}^{2}$ & 0.87 & 1 \\
\hline Root mean square error, RMSE & 3.072428 & 0.000 \\
\hline
\end{tabular}

Table 4: Comparison of prediction performance of ANN and regression models for tensile strength.

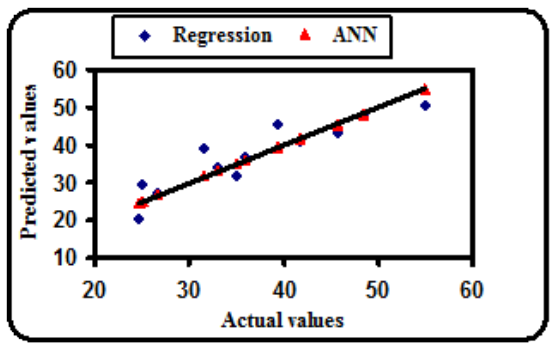

Figure 2: Actual against predicted values using ANN and regression models for tensile strength.

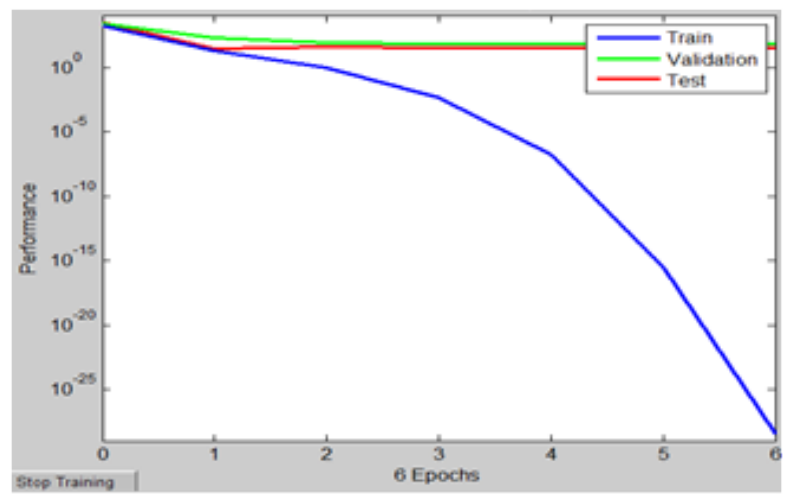

Figure 3: The performance plot of the ANN used to predict the fabric tensile strength.

multi-linear regression model with the experimentally actual tensile strength of woven fabrics. It is observed that ANN model reproduced the trend in the measured values better than regression model; and the ANN model has more capability of making quantitatively accurate tensile strength predictions. The correlation coefficient between actual and predicted yarn tensile strength using ANN and regression models were 1 and 0.94, respectively (Tables 3 and 4) (Figures 2 and 3).

Figure 3 describes the performance training algorithm for the ANN used to predict the tensile strength of the woven fabrics. This is a useful diagnostic tool to plot the training, validation, and test errors to check the progress of training. This figure describes that the test set error and the validation set error has similar characteristics, and it does not appear that any significant over fitting has occurred. The training stopped after 6 iterations because the validation error increased.

\section{Breaking extension}

Equally important to the fabric strength is its ability to extend under load. When the fabric is subjected to tension in one direction, the extension takes place in two main phases. The first phase is decrimping or crimp removal in the direction of the load. The removal of the crimp is accompanied by a slow rate of increase of the load. The second phase is the extension of the yarn during which the fabric becomes stiffer; the stiffness depends mainly on the character of the yarn. The more is the crimp in the yarn, the more extensible is the fabric $[29,30]$.

Actual and predicted values of breaking extension of the woven fabrics under study and their predicted errors are listed in Table 5. A Comparison between the performances of the ANN and multiple linear-regression models on the data-sets is provided in Table 6.

It can be noticed that ANN model achieved an average RMSE of 0.0006. Comparing this value to the regression model with an average RMSE of 0.1 .2 , suggested that the ANN model highly superior to the regression one.

It is also observed that the artificial neural network model has a capability of achieving a very good fit to the measured breaking extension values as noticed by high $\mathrm{R}^{2}$ value of 0.9999 . While the $\mathrm{R}^{2}$ value associated with the multi linear - regression model was lower to large extent $\left(\mathrm{R}^{2}=0.67\right)$, which means that regression model failed to interpret $37 \%$ of the total variation in the breaking extension values of the woven fabric under study. The poor performance of the regression model in predicting the breaking extension values may be ascribed to this model may be nonlinear.

As seen from Table 5, the predicted errors associated with ANN models were all close to zero, while that associated with regression one range between 6 and 12\%, which confirms the high-ability of ANN model to predict the breaking extension values of woven fabrics. Figure 4 illustrated the predicted breaking extension values of ANN and regression models. From this figure it can be seen that a good agreement between actual and predicted values for ANN model assuring that the predicted errors nonsexist. Whereas the predicted values in the regression model are randomly distributed around the regression line. This confirms that ANN model can perform good prediction with very minor errors.

The performance of the artificial neural network used to predict the breaking extension at the validation, test and training stages were depicted in Figure 5. It can be seen that validation and testing errors have nearly the same characteristics. This type of ANN attains their performance goal after five iterations (Table 6) (Figures 4 and 5).

\begin{tabular}{|l|c|c|c|c|}
\hline \multirow{2}{*}{ Actual values } & \multicolumn{2}{|c|}{ Multi-linear regression } & \multicolumn{2}{|c|}{ Artificial neural network } \\
\cline { 2 - 5 } & $\begin{array}{c}\text { Predicted } \\
\text { value }\end{array}$ & $\begin{array}{c}\text { Absolute } \\
\text { error (\%) }\end{array}$ & $\begin{array}{c}\text { Predicted } \\
\text { value }\end{array}$ & $\begin{array}{c}\text { Absolute } \\
\text { error (\%) }\end{array}$ \\
\hline 18.33333 & 20.37963 & 11.16161 & 18.33342 & 0.000489 \\
\hline 23 & 22.24074 & 3.301130 & 22.99990 & 0.000399 \\
\hline 24.66667 & 23.15741 & 6.118608 & 24.66657 & 0.000382 \\
\hline 20 & 21.29630 & 6.4815 & 20.00003 & 0.000156 \\
\hline
\end{tabular}

Table 5: Breaking extension predicted by multi-linear regression and neura network.

\begin{tabular}{|l|c|c|}
\hline Statistical parameters & Regression & ANN \\
\hline Coefficient of determination, $\mathrm{R}^{2}$ & 0.67 & 0.9999 \\
\hline Root mean square error, RMSE & 1.2479 & 0.0006 \\
\hline
\end{tabular}

Table 6: Comparison of prediction performance of ANN and regression models for breaking extension. 


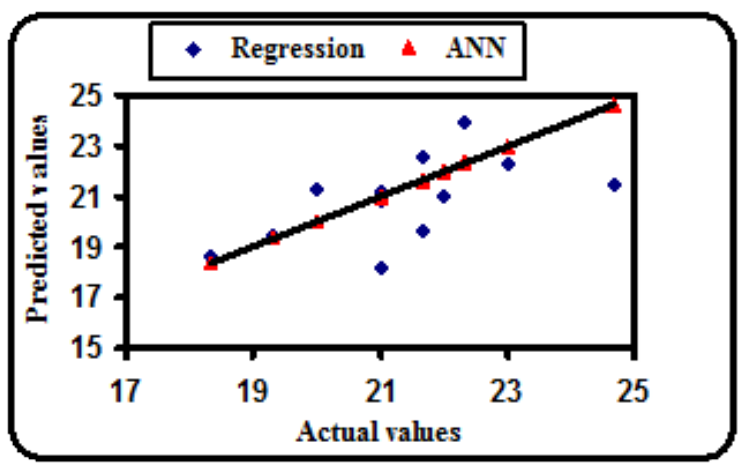

Figure 4: Actual against predicted values using ANN and regression models for breaking extension.

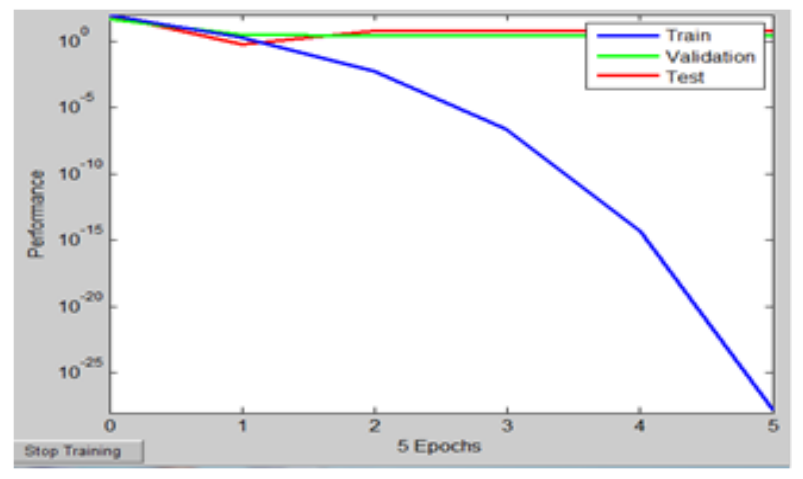

Figure 5: The performance plot of the ANN used to predict the fabric breaking extension.

\begin{tabular}{|l|c|c|c|c|}
\hline \multirow{2}{*}{ Actual values } & \multicolumn{2}{|c|}{ Multi-linear regression } & \multicolumn{2}{c|}{ Artificial neural network } \\
\cline { 2 - 5 } & $\begin{array}{c}\text { Predicted } \\
\text { value }\end{array}$ & $\begin{array}{c}\text { Absolute } \\
\text { error (\%) }\end{array}$ & $\begin{array}{c}\text { Predicted } \\
\text { value }\end{array}$ & $\begin{array}{c}\text { Absolute } \\
\text { error (\%) }\end{array}$ \\
\hline 11 & 9.518518 & 13.46802 & 10.7 & 2.835158 \\
\hline 22 & 21.25926 & 3.367 & 21.8 & 1.04382 \\
\hline 30.3333 & 28.50926 & 6.013325 & 30.2 & 0.286504 \\
\hline 34 & 33.34259 & 1.933559 & 34.1 & 0.29391 \\
\hline
\end{tabular}

Table 7: Air permeability predicted by multi-linear regression and neural network.

\section{Air permeability}

The air permeability is a very important factor in the performance of some textile materials. Especially, it is taken into consideration for clothing, parachutes, sails, vacuum cleaner, fabrics for air bags and industrial filter fabrics. The air permeability is mainly dependent upon the fabric's weight and construction (thickness and porosity).

The actual and predicted values of air permeability of woven fabrics and their absolute errors for ANN and regression models were listed in Table 7. From this table, it can be observed that the absolute errors of the air permeability predicted by ANN model are highly lower compared to those predicted by regression model. The predicted errors of the air permeability associated by ANN model ranges between 0.3 and 3\%, whereas the corresponding errors associated with regression model falls between 2 and $13 \%$. The lower predicted errors accompanied by ANN model give a high degree of confidence in this type of prediction models.

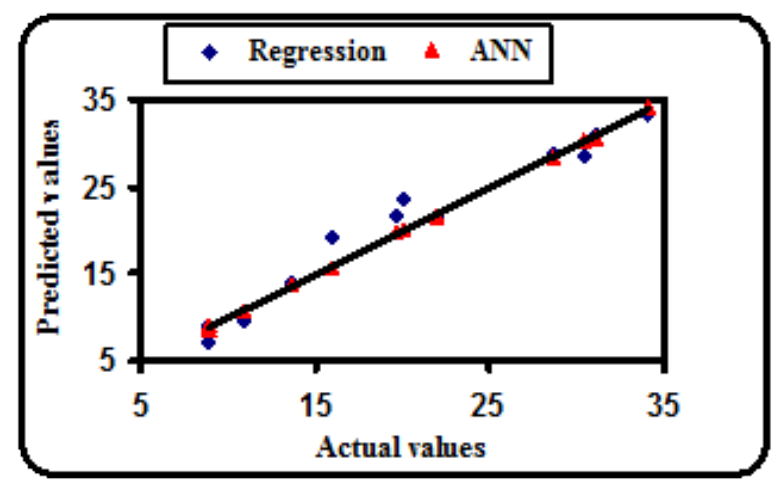

Figure 6: Actual against predicted values using ANN and regression models for air permeability.

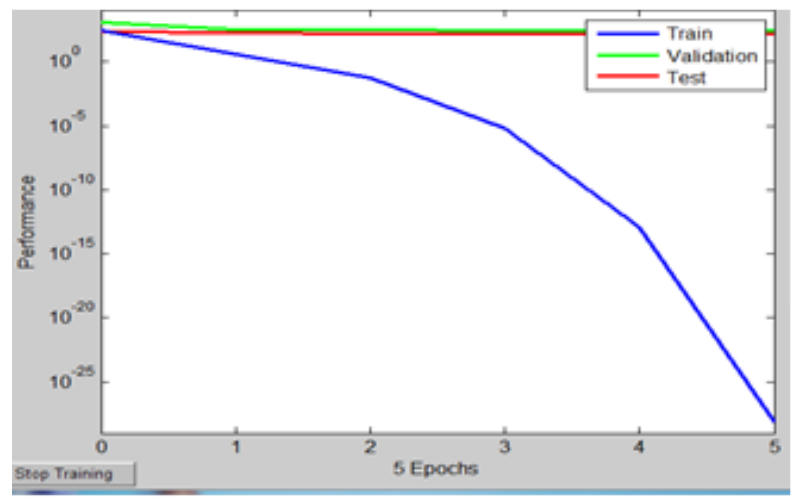

Figure 7: The performance plot of the ANN used to predict the fabric air permeability.

\begin{tabular}{|l|c|c|}
\hline Statistical parameters & Regression & ANN \\
\hline Coefficient of determination, $\mathrm{R}^{2}$ & 0.95 & 1 \\
\hline Root mean square error, RMSE & 4.4776 & 1.08807 \\
\hline
\end{tabular}

Table 8: Comparison of prediction performance of ANN and regression models for air permeability.

The $\mathrm{R}^{2}$ and RMSE values of air permeability of the woven fabrics under study predicted by ANN and regression models are presented in Table 8 . The average $\mathrm{R}^{2}$ and RMSE values predicted via ANN model are 1 and 1.09 , respectively. While such values predicted using regression model are 0.95 and 4.5 for $\mathrm{R}^{2}$ and RMSE, respectively. The coefficient of determination values show that ANN model explained about $100 \%$ of the variations in the air permeability, whereas the variations explained by the regression model approaches $95 \%$.

The air permeability values of the woven fabrics predicted by ANN and the regression models were depicted in Figure 6. From this figure it can be observed that the agreement between the actual values of air permeability and that predicted by ANN model is very high; while the agreement between the corresponding values predicted by the regression model is lower to some extent. The correlation coefficient between actual values of air permeability and that predicted by ANN model is approximately 1 ; while the correlation coefficient between the corresponding values for regression model equals to 0.95 . Therefore, ANN model can perform good prediction with least error compared to regression one (Tables 7 and 8) (Figures 6 and 7). 
Citation: Abou-Nassif GA (2015) Predicting the Tensile and Air Permeability Properties of Woven Fabrics Using Artificial Neural Network and Linear Regression Models. J Textile Sci Eng 5: 209. doi:10.4172/2165-8064.1000209

Figure 7 depicts the plot of the performance of the ANN used to predict the fabric air permeability at training, validation and testing stages. It is shown that this neural network attains their optimum performance after 5 epochs, whereas the training and validation errors have the same characteristics.

\section{Conclusion}

In this study, tensile properties and air permeability of woven fabrics were predicted using ANN and regression models. The independent variables in the predicted models were weft yarn count $(\mathrm{Ne})$, twist multiplier and weft density (ppi). Dependent variables which predicted by ANN and regression models were tensile strength, breaking extension and air permeability. The findings of this study revealed that $\mathrm{R}^{2}$ values associated with ANN models for all fabric properties were very high compared to the $\mathrm{R}^{2}$ values accompanied the regression models. Also, the RMSE values with ANN models are lower than those associated with regression ones. All absolute errors of the fabric properties predicted by ANN model were highly lower than that errors predicted by the regression model. Good agreement between predicted and actual values of tensile strength, breaking extension and air permeability of the woven fabrics proves that the neural network is an effective technique. With the help of the neural network, we can predict woven fabric properties easily, effectively and accurately.

\section{References}

1. Zadeh $L$ (1994) Soft computing and fuzzy logic. IEEE Software 11: 48-56.

2. Keeler $J(1992)$ Vision of neural networks and fuzzy logic for prediction and optimization of manufacturing processes, In: Applications of artificial neural networks III. 1709: 447-456.

3. Haykin S (1998) Neural networks: A comprehensive foundation. Prentice Hall, New York.

4. Lippman RP (1987) An introduction to computing with neural nets. IEEE ASSP Magazine 4-22.

5. Ahmed AA, Idrees HF, Hebeish Ali Ali (2014) Predicting the tensile properties of cotton/ spandex core-spun yarns using artificial neural networks and regression models. The Journal of the Textile Institute 105: 1221-1229.

6. Ogulata SN, Sahin C, Ogulata RT (2006) The prediction of elongation and recovery of woven bi-stretch fabric using artificial neural network and linear regression models. Journal of Fibers and Text in East Euro 14: 46-49.

7. Beltran R, Wang L, Wang $X$ (2004) Predicting spinning performance with an artificial neural network model. Text Res J 74: 757-763.

8. Majumdar A, Majumdar PK, Sarkar B (2005) Application of linear regression, artificial neural network and neuro-fuzzy algorithms to predict the breaking elongation of rotor-spun yarns. Indian J Fibers Text Res 30: 19-25.

9. Ahmed, AA Mourad MM, Ali HA, Mohamed AR (2015) Comparison between physical properties of ring-spun yarn and compact yarns spun from different pneumatic compacting systems. Indian Journal of Fibers and Textile Research 40: 43-50.

10. Pinar D, Osman B, Rizvan E (2006) Prediction of strength and elongation properties of cotton/polyester blended yarn. Fibers and Textiles in Eastern Europe 14: 18-21.

11. Hearle JWS, El-Behery HM, Thakur VM (1961) The mechanics of twisted yarns: Theoretical developments. Journal of the Textile Institute Transactions 52: T197-T220.

12. Frydrych I (1992) A new approach for predicting strength properties of yarn Textile Research Journal 62: 340-348.
13. Vitro C, Paul C (2009) Yarn irregularity parameterization using optical sensors. Fibers and Textiles in Eastern Europe 17.

14. Lucas LJ (1983) Mathematical fitting of modulus-strain curves of poly (ethylene terephthalate) industrial yarns. Textile Research Journal 53: 771-777.

15. Kim YK, El-sheikh A (1984) Tensile behavior of twisted hybrid fibrous structures Part II: Experimental studies. Textile Research Journal 54: 534-543.

16. Kim AYK, El-Shiekh A (1984) Tensile behavior of twisted hybrid fibrous structures. Part I: Theoretical investigation. Textile Research Journal 54 526-534.

17. El Mogahzy YE (1988) Selecting cotton fiber properties for fitting reliable equation to HVI data. Textile Research Journal 58: 392-397.

18. Hunter $L$ (1988) Prediction of cotton processing performance and yarn properties from HVI test results. Melliand Textilber 4: 229-232.

19. Ahmed AA, Mourad MM (2014) Effects of spandex drawing ratio and weave structure on the physical properties of cotton/spandex woven fabrics. The Journal of the Textile Institute 105: 235-245.

20. Mourad MM, Ahmed ES, Ahmed AA (2011) Core spun yarn and the secret behind its popular appeal. Textile Asia 41-43.

21. Fan J, Hunter L (1998) A worsted fabric expert system. Part II: An artificial neural network model for predicting the properties of worsted fabrics. Textile Research Journal 68: 763-771.

22. Ramesh MC, Rajamanickam R, Jayaraman S (1995) The prediction of yarn tensile properties by using artificial neural networks. The Journal of the Textile Institute 86: 459-469.

23. Hadizadeh M, Jeddi AAA, Tehran MA (2009) The prediction of initial loadextension behavior of woven fabrics using artificial neural network. Text Res J 79: 1599-1609.

24. Youssefi M, Faez K (1999) Fabric Handle Prediction Using Neural Networks, Proceedings of the IEEE-EURASIP Workshop on Nonlinear Signal and Image Processing (NSIP'99), Bogaziçi University Printhouse, Antalya, Turkey.

25. Hui CL, Lau TW, Ng SF, Chan KCC (2004) Neural network prediction of human psychological perceptions of fabric hand. Text Res J 74: 375-383.

26. Matsudaira M (2006) Fabric handle and its basic mechanical properties. J of Textile Engineering 52: 1-8

27. Fan J, Newton E, Au R, Chan SCF (2001) Predicting garment drape with a fuzzy-neural network text. Res J 71: 605-608.

28. Eid MY, Alsalmawy A, Almetwally AA (2010) Performance of woven fabrics containing spandex. Indian Textile Journal 120: 1-22.

29. Mansour SA, Morsy AE, Almetwally S (1998) Twist loss on Air - Jets: Effects on Various Fabric Properties. The Indian Textile Journal 41: 1-12.

30. Tugrul O (2006) Air permeability of woven fabrics. Journal of Textile and Apparel, Technology and Management 5: 1-10. 